\title{
Monoclonal antibodies in rheumatoid arthritis: comparative effectiveness of tocilizumab with tumor necrosis factor inhibitors
}

This article was published in the following Dove Press journal:

Biologics:Targets and Therapy

7 April 2014

Number of times this article has been viewed

\section{Toshio Tanaka ${ }^{1,2}$ \\ Yoshihiro Hishitani ${ }^{3}$ \\ Atsushi Ogata ${ }^{2,3}$}

'Department of Clinical Application of Biologics, Osaka University

Graduate School of Medicine, Osaka University, Osaka, Japan; ${ }^{2}$ Department of Immunopathology, WPI Immunology Frontier Research Center, Osaka University, Osaka, Japan; ${ }^{3}$ Department of Respiratory Medicine, Allergy and Rheumatic Diseases, Osaka University Graduate School of Medicine, Osaka University, Osaka, Japan
Correspondence: Toshio Tanaka Department of Clinical Application of Biologics, Osaka University Graduate School of Medicine, 2-2 Yamada-oka, Suita City, Osaka 565-087I, Japan

$\mathrm{Tel}+81668793838$

Fax+8I668793839

Email ttanak@imed3.med.osaka-u.ac.jp

\begin{abstract}
Rheumatoid arthritis (RA) is a chronic inflammatory disease characterized by persistent joint inflammation, systemic inflammation, and immunological abnormalities. Because cytokines such as tumor necrosis factor (TNF)- $\alpha$ and interleukin (IL)-6 play a major role in the development of RA, their targeting could constitute a reasonable novel therapeutic strategy for treating RA. Indeed, worldwide clinical trials of TNF inhibiting biologic disease modifying antirheumatic drugs (bDMARDs) including infliximab, adalimumab, golimumab, certolizumab pegol, and etanercept as well as the humanized anti-human IL- 6 receptor antibody, tocilizumab, have demonstrated outstanding clinical efficacy and tolerable safety profiles, resulting in worldwide approval for using these bDMARDs to treat moderate to severe active RA in patients with an inadequate response to synthetic disease modifying antirheumatic drugs (sDMARDs). Although bDMARDs have elicited to a paradigm shift in the treatment of RA due to the prominent efficacy that had not been previously achieved by sDMARDs, a substantial percentage of patients failed primary or secondary responses to bDMARD therapy. Because RA is a heterogeneous disease in which TNF- $\alpha$ and IL- 6 play overlapping but distinct pathological roles, further studies are required to determine the best use of TNF inhibitors and tocilizumab in individual RA patients.
\end{abstract}

Keywords: interleukin-6, rheumatoid arthritis, adalimumab, biologic

\section{Introduction to rheumatoid arthritis (RA) and the development of targeted therapies}

RA, a chronic disease affecting $0.5 \%-1 \%$ of adults, is characterized by persistent synovitis, systemic inflammation, and immunological abnormalities. ${ }^{1,2}$ Uncontrolled active RA causes joint damage, disability, diminished quality of life, and cardiovascular and other comorbidities. Although its exact pathogenesis is not fully understood, a multistep progression has been proposed for the development of RA. ${ }^{1}$ Environment-gene interactions promote a loss of tolerance to self-antigens that contain a citrulline residue generated by posttranslational modification, leading to an anticitrulline response by both T-cells and B-cells. Thereafter, the inflammatory response becomes localized in the joints and synovitis is initiated and perpetuated by positive feedback loops, promoting systemic disorders. Lymphocytes, other inflammatory cells, and their products contribute to the development of RA. For instance, many cytokines have been implicated in the pathogenesis of RA, including tumor necrosis factor (TNF)- $\alpha$, interleukin (IL)-1, IL-6, IL-7, IL-15, IL-17A, IL-17F, IL-18, IL-21, IL-23, IL-32, IL-33, and granulocyte-macrophage colony stimulating factor. ${ }^{1}$

Because TNF- $\alpha$ is an important mediator responsible for joint inflammation and destruction, it was the first cytokine to be targeted in the treatment of RA., ${ }^{2,3}$ 
TNF- $\alpha$ is overexpressed in the synovial fluid of patients with RA. Moreover, TNF- $\alpha$ transgenic mice spontaneously develop arthritis. The first biologic disease modifying antirheumatic drugs (bDMARD) generated was infliximab (IFX), a chimeric monoclonal antibody (mAb) to TNF- $\alpha$. Clinical trials of IFX proved that TNF blockade is highly efficacious in the treatment of RA and led to the development of other TNF inhibitors.

Another cytokine that has been targeted in the treatment of RA is IL-6, a typical cytokine featuring redundancy and pleiotropic activity that plays a key role in the development of RA. ${ }^{4-6}$ IL- 6 promotes the development of an imbalance between Th17 and regulatory $\mathrm{T}$ (Treg) cells and the production of autoantibodies, such as rheumatoid factor and anticitrullinated peptide antibody. IL-6 also promotes synovial inflammation and cartilage and bone destruction and has systemic effects in cardiovascular, psychological, and skeletal disorders. The first generated bDMARD targeting IL-6 was tocilizumab (TCZ), a humanized anti-IL-6 receptor antibody. Now, other IL-6 inhibitors are also being developed and clinical trials for these agents are in progress. ${ }^{6}$ These include fully human anti-IL-6 receptor mAb (REGN88/SAR153191 [sarilumab]), anti-IL-6 receptor nanobody (ALX-0061), antiIL-6 Abs (CNTO136 [sirukumab], ALD518 [BMS-945429], CDP6038 [olokizumab], and MEDI5117). In this review, we highlight current data regarding the comparative efficacy and safety of TCZ and TNF inhibitors. We also discuss the positions of these agents in the treatment of RA.

\section{Differential pharmacology of TCZ, adalimumab (ADA), and other TNF inhibitors}

Several bDMARDs are currently available for the treatment of moderate to severe active RA, including five TNF inhibitors (IFX, ADA, golimumab [GOL], certolizumab pegol [CEP], and etanercept [ETA]), an IL-6 blocker (TCZ), a T-cell stimulator blocker (abatacept), a B-cell depletory (rituximab), and an IL-1 receptor antagonist (anakinra)., The characteristic features of TCZ and five TNF inhibitors are shown in Table 1.

TCZ is a humanized IgG1 class anti-IL-6 receptor $\mathrm{mAb}$ that was generated by grafting the complementarity determining regions of a mouse antihuman IL-6 receptor antibody $(\mathrm{Ab})$ into human IgG1. ${ }^{7}$ TCZ blocks IL-6 mediated signal transduction by inhibiting the binding of IL- 6 to both transmembrane and soluble IL-6 receptors. TCZ can be administered intravenously or subcutaneously.

IFX was the first TNF inhibitor developed and it is a chimeric immunoglobulin (Ig) composed of a murine variable region and a human constant region against TNF- $\alpha$. Due to immunogenicity and response failure issues, IFX is licensed to be used with methotrexate (MTX) by intravenous injection. ADA and GOL are fully human mAbs to TNF- $\alpha$ and can be used subcutaneously every 2 weeks and every 4 weeks, respectively. CEP is a humanized Fab fragment conjugated to polyethylene glycol (PEG). The attachment of PEG prolongs the drug's half-life, whereas the absence of an Fc fragment prevents effector functions such as Abdependent cellular cytotoxicity and complement-dependent cellular cytotoxicity, as well as active transfer of CEP across the placenta during pregnancy. CEP is used subcutaneously every 2 weeks.

In contrast to these TNF inhibitors, ETA is a fusion protein consisting of two TNF receptor 2 (also known as p75TNF receptor) extracellular domains and a human $\mathrm{Fc}$ fragment of the IgG1 class. As TNF- $\alpha$ and lymphotoxin binds to TNF receptor 2 , ETA neutralizes the biological activity of both cytokines. ETA is administered subcutaneously once or twice weekly.

\section{Comparative efficacy studies of TCZ,ADA, and other TNF inhibitors TCZ}

The efficacy of TCZ administered alone or in combination with MTX or other synthetic disease modifying antirheumatic

Table I Characteristics of tocilizumab and tumor necrosis factor inhibitors

\begin{tabular}{lllllll}
\hline & Tocilizumab & Infliximab & Adalimumab & Golimumab & Certolizumab pegol & Etanercept \\
\hline Target molecule & IL-6R & TNF- $\alpha$ & TNF- $\alpha$ & TNF- $\alpha$ & TNF- $\alpha$ & TNF- $\alpha$ \\
& & & & & & Lymphotoxin \\
Structure & Humanized Ig & Chimeric Ig & Fully human Ig & Fully human Ig & Humanized Fab-pegol & P75TNFR-Fc \\
$\begin{array}{l}\text { Injection route } \\
\text { Activity }\end{array}$ & IV, SC & IV & SC & SC & SC & SC \\
ADCC & + & & & & & + \\
CDCC & + & + & + & + & - & \pm \\
\hline
\end{tabular}

Abbreviations: ADCC, antibody-dependent cellular cytotoxicity; CDCC, complement-dependent cellular cytotoxicity; Ig, immunoglobulin; IL-6R, interleukin-6 receptor; IV, intravenously; SC, subcutaneously; TNF- $\alpha$, tumor necrosis factor- $\alpha$; TNFR, TNF receptor. 
drugs (sDMARDs) was verified for active RA in seven Phase III trials. The three Phase III trials AMBITION, SAMURAI, and SATORI were designed to examine the efficacy of TCZ monotherapy. ${ }^{8-10}$ The AMBITION trial ${ }^{8}$ involved active RA patients for whom previous treatment with MTX and TNF inhibitors had not failed. The SAMURAI trial ${ }^{9}$ involved patients with an inadequate response to sDMARDs, and the SATORI trial ${ }^{10}$ involved patients with an inadequate response to MTX. In all three studies, patients treated with TCZ had superior American College of Rheumatology (ACR) 20 responses and lower disease activity score (DAS) 28 at 24 weeks than controls treated with MTX or other sDMARDs.

Four Phase III trials were performed to evaluate the efficacy of TCZ combination therapy with MTX or another SDMARD. The OPTION trial was designed to evaluate the efficacy of TCZ in combination with MTX, and the results showed that combination therapy is effective for moderate to severe active RA. ${ }^{11}$ The TOWARD trial demonstrated that TCZ combined with a SDMARD such as MTX, chloroquine, gold, sulphasalazine, azathioprine, or leflunomide is effective for reducing RA disease activity in patients with an inadequate response to monotherapy with any one of the sDMARDs. ${ }^{12}$ The RADIATE trial proved that TCZ plus MTX is effective for achieving rapid and sustained improvements in signs and symptoms in patients whose RA is refractory to TNF inhibitors. ${ }^{13}$ Moreover, the LITHE trial, which was designed to evaluate not only disease activity but also structural joint damage, demonstrated that TCZ plus MTX is efficacious at suppressing disease activity. ${ }^{14}$ Radiographic evidence from the LITHE trial showed that progression of joint destruction is significantly inhibited after 52 weeks of combination treatment. ${ }^{14}$ All of these studies enrolled patients with an inadequate response to all previous treatments, including MTX, TNF inhibitors, or other sDMARDs, and all of the studies showed that TCZ combination therapy is effective for these patient populations.

\section{ADA}

The efficacy and safety of ADA was examined in the ARMADA trial. ${ }^{15}$ A total of 271 patients with active RA who had an inadequate response to MTX were randomized to continue MTX in combination with either placebo or ADA (20, 40, or $80 \mathrm{mg}$ subcutaneously every other week). ACR20 responses at week 24 were $47.8,67.2$, and $65.8 \%$ in the 20 , 40 , and $80 \mathrm{mg}$ groups, respectively, whereas the response rate was $14.5 \%$ for the placebo group. Subsequently, the PREMIER study, which involved 799 patients with early and aggressive RA who had no previous MTX use, confirmed that ADA plus MTX combination therapy is vastly superior to either MTX alone or ADA alone in improving clinical signs and symptoms, inhibiting radiographic progression of joint destruction, and effecting clinical remission. ${ }^{16}$

\section{IFX}

In the Phase III trial ATTRACT, 428 RA patients with active disease activity and an inadequate response to MTX were randomized to receive MTX with either placebo or IFX ( $3 \mathrm{mg} / \mathrm{kg}$ every 4 weeks, $3 \mathrm{mg} / \mathrm{kg}$ every 8 weeks, $10 \mathrm{mg} / \mathrm{kg}$ every 4 weeks, or $10 \mathrm{mg} / \mathrm{kg}$ every 8 weeks). ${ }^{17}$ At week 30 , patients in the IFX treated groups achieved an ACR20 response rate of $50 \%-58 \%$, versus an ACR20 response rate of only $20 \%$ in the placebo group. Structural damage was also assessed with the modified van der Heijde-Sharp score at week $102 .{ }^{18}$ Compared with the MTX only regimen, erosion and joint space narrowing scores from baseline to week 102 with early RA patients decreased significantly with each of the IFX dose regimens.

\section{GOL}

In the Phase III trial GO-FORWARD, 444 active RA patients who had an inadequate response to MTX were randomly assigned to receive placebo subcutaneous injections plus MTX, GOL $100 \mathrm{mg}$ plus placebo capsules, GOL $50 \mathrm{mg}$ plus MTX, or GOL $100 \mathrm{mg}$ plus MTX. ${ }^{19}$ The proportion of patients who achieved an ACR20 response at week 14 was $33.1 \%$ in the placebo plus MTX group, $44.4 \%(P=0.059)$ in the GOL $100 \mathrm{mg}$ plus placebo group, $55.1 \%(P=0.001)$ in the GOL $50 \mathrm{mg}$ plus MTX group, and $56.2 \%(P<0.001)$ in the GOL 100 mg plus MTX group. At week 24, median Health Assessment Questionnaire Disease Index (HAQ-DI) score improvements from baseline for the placebo plus MTX, GOL $100 \mathrm{mg}$ plus placebo, GOL $50 \mathrm{mg}$ plus MTX, and GOL $100 \mathrm{mg}$ plus MTX groups were $0.13,0.13$ ( $P=0.240), 0.38$ $(P<0.001)$, and $0.50(P<0.001)$, respectively.

\section{CEP}

In the Phase III trial Rapid-1, 982 active RA patients were randomized to receive subcutaneous CEP at an initial dose of $400 \mathrm{mg}$ given at weeks 0,2 , and 4 , with a subsequent dosage of 200 or $400 \mathrm{mg}$ every 2 weeks plus MTX, or placebo plus $\mathrm{MTX}^{20}$ At week 24, the ACR20 response rates were $13.6 \%, 58.8 \%$, and $60.8 \%$ for the placebo, CEP $200 \mathrm{mg}$, and CEP $400 \mathrm{mg}$ groups, respectively. At week 52, mean radiographic progression from baseline was reduced in patients treated with CEP $200 \mathrm{mg}$ (0.4 Sharp units) or $400 \mathrm{mg}$ 
(0.2 Sharp units), compared with placebo treated patients (2.8 Sharp units, $P<0.001$ ).

\section{ETA}

In a Phase II study, 234 active RA patients who had an inadequate response to previous treatment regimens including MTX were randomly assigned to receive twice weekly subcutaneous injections of ETA (10 or $25 \mathrm{mg}$ ) or placebo for 24 weeks. At week 24, the ACR20 response rates were 51\%, $59 \%$, and $11 \%$ in the ETA $10 \mathrm{mg}$, ETA $20 \mathrm{mg}$, and placebo groups, respectively. ${ }^{21}$ In the subsequent Phase III TEMPO trial, 682 patients with active RA were randomly allocated to treatment with ETA $25 \mathrm{mg}$ (subcutaneously twice weekly), oral MTX, or the combination. ${ }^{22}$ The numeric index of the ACR response area under the curve over the first 24 weeks was significantly greater in the combination group than the ETA alone or MTX alone groups $(P<0.0001)$. Moreover, at week 52, the combination was more efficacious than ETA alone or MTX alone in protecting against joint damage (mean total Sharp score: -0.54 versus $0.52, P=0.0006 ;-0.54$ versus $2.80, P<0.0001$, respectively).

\section{Indirect comparisons of the efficacy of TCZ and TNF inhibitors}

As indicated above, the efficacy of TCZ and TNF inhibitors in treating moderate to severe RA in patients who experienced an inadequate response to MTX has been demonstrated in separate studies. Although several systematic reviews have indirectly compared the efficacy of TCZ and TNF inhibitors in treating RA, only one trial, the ADACTA, has directly compared the efficacy of these agents. ${ }^{23}$

Bergman et al conducted a systematic literature review of double blind, randomized, placebo-controlled trials that spanned an 18-year period and investigated the effectiveness of TCZ (three trials; OPTION, LITHE, and TOWARD) and TNF inhibitors ADA, IFX, and ETA (total 11 trials) in treating RA in patients who experienced an inadequate response to sDMARDs. ${ }^{24}$ The effectiveness of TCZ is comparable to that of each of the TNF inhibitors with respect to ACR20 and ACR50 responses, but greater than that of the TNF inhibitors with respect to ACR70 response. Another systematic review of selected clinical trials involving combination therapy with MTX concluded that there was no difference in efficacy on the basis of ACR50 response criterion at 24/30 weeks between TNF inhibitors and TCZ. ${ }^{25}$ Turkstra et al reported a mixed treatment comparison of the short-term efficacy of nine bDMARDs, including TNF inhibitors and TCZ in patients with established RA. ${ }^{26}$
They found that the ACR50 response rate of TCZ at 6 months is comparable to that of ADA, ETA, GOL, and IFX. In an indirect comparison, Salliot et al found no significant difference in the efficacy of TCZ and GOL in treating RA patients who had an inadequate response to TNF inhibitors (ADA, ETA, and IFX). ${ }^{27}$ Orme et al reported the results of a network meta-analysis of the efficacy of bDMARDs with or without sDMARDs. ${ }^{28}$ Odds ratios (covariate analysis) of ACR20/50/70 responses for ADA plus sDMARDs and TCZ plus sDMARDs versus sDMARDs alone were $3.374 / 4.203 / 4.58$ and 4.363/5.797/9.23, respectively. In contrast, odds ratios (fixed effect) of ACR20/50/70 responses for ADA and TCZ versus placebo were 4.95/4.82/11.42 and 26.17/46.94/55.54, respectively. Pierreisnard et al also reported that there were no significant differences between the various TNF inhibitors and TCZ in terms of clinical efficacy (ACR50) in patients who had an inadequate MTX response. ${ }^{29}$ Jones et al summarized the evidence regarding radiographic damage with bDMARDs, either alone or in combination with MTX..$^{30}$ For biologic monotherapy, TCZ, ADA, and ETA were significantly better than MTX, with TCZ ranking first, whereas GOL had no significant effect (Figure 1). For a bDMARD in combination with MTX compared with MTX alone, TCZ and all TNF inhibitors were effective at slowing X-ray progression. Taken together, the evidence from these indirect comparisons indicates that the efficacy of TCZ is comparable to that of TNF inhibitors when used in combination with MTX and that TCZ monotherapy is superior to TNF inhibitor monotherapy.

\section{Direct comparisons of the efficacy of TCZ and ADA}

The head-to-head ADACTA trial compared the efficacy of TCZ with that of ADA as monotherapy for RA..$^{23} \mathrm{~A}$ total of 325 patients were randomly assigned to receive either TCZ $8 \mathrm{mg} / \mathrm{kg}$ intravenously every 4 weeks plus placebo subcutaneously every 2 weeks or ADA $40 \mathrm{mg}$ subcutaneously every 2 weeks plus placebo intravenously every 4 weeks for 24 weeks. At week 24, patients treated with TCZ had a greater decrease in DAS28 than patients treated with ADA $(-3.3$ versus $-1.8 ; P<0.0001)$. The proportion of patients attaining DAS28 remission was $39.9 \%$ with TCZ and $10.5 \%$ with ADA. ACR20, ACR50, and ACR70 response rates were achieved in $65 \%$ and $49.4 \%(P<0.01), 47.2 \%$ and $27.8 \%$ $(P<0.01)$, and $32.5 \%$ and $17.9 \%(P<0.01)$ of patients treated with TCZ and ADA, respectively. These results demonstrated the overall superiority of monotherapy with TCZ compared with monotherapy with ADA for the treatment 


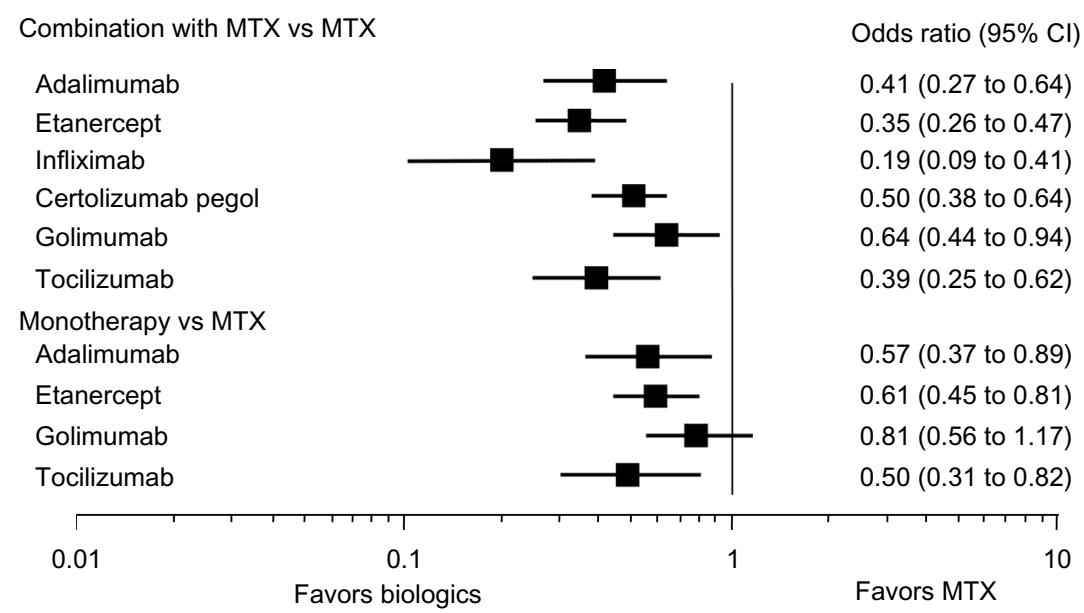

Progression of radiographic damage

Figure I Indirect comparisons of the suppressive effects of tocilizumab and tumor necrosis factor inhibitors on radiographic damage.

Notes: Copyright (c) 2012. Adapted from Dove Medical Press. Jones G, Darian-Smith E, Kwok M, Winzenberg T. Effect of biologic therapy on radiological progression in rheumatoid arthritis: what does it add to methotrexate? Biologics. 2012;6:155-161. ${ }^{30}$ In combination with methotrexate (MTX) compared with MTX alone, tocilizumab and all tumor necrosis factor inhibitors are effective at slowing X-ray progression. As monotherapy, adalimumab, etanercept, and tocilizumab are significantly better than MTX, whereas golimumab had no significant effect. The $\mathrm{x}$-axis shows progression of radiographic damage.

Abbreviations: $\mathrm{Cl}$, confidence interval; MTX, methotrexate.

of RA. Clinical evidence demonstrated that coadministration of TNF inhibitors and MTX is more efficacious than administration of TNF inhibitors alone in treating RA. ${ }^{31}$ In contrast, the findings of the ACT-RAY trial comparing the efficacy of TCZ plus MTX therapy with that of TCZ monotherapy in a setting that closely resembled a real life clinical practice showed that TCZ monotherapy is not clinically inferior to TCZ combination therapy, ${ }^{32}$ indicating that as monotherapy, TCZ appears to be more effective than TNF inhibitors at suppressing disease activity.

In a Japanese cohort, the Tsurumai Biologics Communication Registry, the proportion of patients who achieved low disease activity, clinical remission, and a moderate or good European League Against Rheumatism (EULAR) response at 24 weeks was determined following treatment with ADA or TCZ. ${ }^{33}$ A total of 120 patients were treated with ADA (77\% of patients in combination with MTX), while 99 patients were treated with TCZ (36\% of patients in combination with MTX). There was no significant difference between ADA and TCZ treated patients with respect to the proportion of low disease activity and remission, but a higher proportion of patients treated with TCZ achieved a moderate or good EULAR response.

\section{Comparative safety and tolerability studies}

The integrated safety of TCZ was evaluated in clinical trials through comparisons of adverse events (AEs) between a control population $(4,199)$ and a TCZ treated population $(4,009)$, and the results were reported in 2011. ${ }^{34}$ Total exposure to TCZ was 8,580 patient-years (PYs), and the total duration of observation was 9,414 PYs. Overall AE and serious AE rates were 278.2/100 PYs and 14.4/100 PYs, respectively. AEs included serious infection (4.7/100 PYs), opportunistic infection (0.23/100 PYs), gastrointestinal perforation $(0.28 / 100 \mathrm{PYs})$, malignancy $(1.1 / 100$ PYs), myocardial infarction (0.25/100 PYs), and stroke (0.19/100 PYs).

In another systematic review in which the total duration of observation was 12,293 PYs, infections were also the most common $\mathrm{AE}$ and serious $\mathrm{AE}$ identified, and the rate of serious infections was 4.5/100 PYs. ${ }^{35}$ The short-term (28 weeks) safety of TCZ was monitored in a postmarketing surveillance study in Japan involving 7,901 patients. ${ }^{36}$ The incidence of total AEs and serious AEs was 43.9\% and $9.6 \%$, respectively. Infection and infestation were the most frequent (11.1\%) and serious (0.5\%) AEs. Analysis of long-term clinical trial safety data showed that rates of serious AEs, serious infections, and cardiovascular events remained stable during continued exposure to TCZ. Infection was identified as the most frequent serious AE. The most common infections reported in randomized controlled trials (RCTs) were pneumonia (0.9/100 PYs) and skin or soft tissue infections (0.9/100 PYs). These results led to the conclusion that infections are the most frequent AEs associated with TCZ. A meta-analysis comparing the safety 
profile of TCZ with those of TNF inhibitors (7-9/100 PYs) showed similar rates of serious infections, ${ }^{37,38}$ although among TNF inhibitors, an increased risk of serious infection was observed with IFX.

As TNF- $\alpha$ plays a crucial role in the host defense against intracellular pathogens (eg, TNF- $\alpha$ activates macrophages and stimulates the formation and maintenance of granulomas to protect against Mycobacterium tuberculosis infection), TNF inhibitors increase the risk of tuberculosis reactivation, as evidenced by clinical trials showing an incidence of $0.4 \%$ with IFX. ${ }^{39}$ Within the anti-TNF biologic cohort, IFX and ADA are associated with a 3- to 4-fold higher risk of reactivation than ETA. ${ }^{40}$ It seems likely that the incidence of reactivation of tuberculosis is lower during TCZ treatment than during anti-TNF treatment, as there are only six reported cases in the worldwide TCZ clinical trials database, which covers $>10,000$ PYs of exposure. ${ }^{41}$ Moreover, according to QuantiFERON assay data, TNF inhibitors (but not TCZ) influence tuberculosis-antigeninduced IFN- $\gamma$ production, ${ }^{42}$ suggesting that TCZ may be safer than TNF inhibitors with respect to reactivation of latent tuberculosis.

In contrast to TNF inhibitors, gastrointestinal perforation appears to be an AE specific to TCZ, with an incidence rate of 1.9-2.8/1,000 PYs. ${ }^{34,43}$ This rate is between the 3.9/1,000 PYs for corticosteroids and 1.3/1,000 PYs for TNF inhibitors, as indicated in the United Health Care database. ${ }^{43}$ A total of 17 of 29 (59\%) reported events involved colonic diverticular perforation, suggesting that TCZ should not be used in patients with a history of diverticulitis.

Increases in mean fasting levels of plasma lipids, such as total cholesterol (TC), low-density lipoprotein (LDL), triglycerides, and high-density lipoprotein (HDL), occur in $20 \%-30 \%$ of patients treated with TCZ, which appeared higher in patients treated with TNF inhibitors. ${ }^{34,36}$ A 24-week, double blind, randomized, multicenter, two part, Phase III trial followed by an 80 -week open label trial (MEASURE) evaluated lipid and lipoprotein levels, HDL particle composition, markers of coagulation, and thrombosis in 132 patients with RA receiving either TCZ or placebo. ${ }^{44}$ At week 12, median TC, LDL-cholesterol (LDL-C), and triglyceride levels increased in TCZ recipients versus placebo recipients $(12.6 \%$ versus $1.7 \%$, $28.1 \%$ versus $2.2 \%, 10.6 \%$ versus $-1.9 \%$, respectively; all $P<0.01$ ). There were no significant differences in the concentrations of mean small LDL, mean oxidized LDL, or total HDL-C, but the HDL associated serum amyloid A
(SAA) content decreased in TCZ treated patients. TCZ also induced reductions $(>30 \%)$ in secretory phospholipase A2-IIA, lipoprotein (a), fibrinogen, and D-dimers and an elevation in the level of paraoxonase (all $P<0.0001$ versus placebo). These data constitute detailed evidence that TCZ modulates lipoprotein particles and other surrogates of vascular risk.

Comparisons of drug survival with TNF inhibitors have been reported in some registries. In the Consortium of Rheumatology Researchers of North America registry, the 24-month persistence for biologically naive patients on the new anti-TNF treatments IFX, ETA, and ADA was $63 \%$, $53 \%$, and $53 \%$ respectively. ${ }^{45}$ The Lombardy Rheumatology Network registry reported 2.5-year treatment continuation rates for IFX, ETA, and ADA of approximately $56 \%$, $72 \%$, and $57 \%$, respectively. ${ }^{46}$ The Swiss Clinical Quality Management for Rheumatoid Arthritis registry reported 2.5-year drug survival rates for IFX, ETA, and ADA of approximately $51 \%, 58 \%$, and $61 \%$, respectively. ${ }^{47}$ An Italian study group (Gruppo Italiano di Studio sulle Early Arthritides registry) reported 2.5-year continuation rates for IFX, ETA, and ADA of approximately $52 \%, 65 \%$, and $52 \%$, respectively. ${ }^{48}$

There are few reports describing TCZ drug survival. The Danish Nationwide Rheumatological Database registry reported 48-, 96-, and 144-week TCZ adherence rates of $61 \%, 54 \%$, and $47 \%$, respectively. ${ }^{49}$ In contrast, the Danish Nationwide Rheumatological Database registry reported 48-month drug survival rates for IFX, ETA, and ADA of $41 \%, 56 \%$, and $52 \%$, respectively. ${ }^{50}$ The Japanese Osaka University Biologics for Rheumatic Diseases registry reported 1-year drug continuation rates for TCZ, IFX, ETA, and ADA of $89 \%, 73 \%, 86 \%$, and $78 \%$, respectively, and 2.5 -year rates of $79 \%, 47 \%, 78 \%$, and $55 \%$, respectively. ${ }^{51}$ In this registry, the continuation rates for TCZ and ETA are significantly higher than those for IFX and ADA. The most frequent reasons given for discontinuation are AEs for TCZ and a lack of efficacy for ADA and IFX. The Registry of Japanese Rheumatoid Arthritis Patients for Long-term Safety reported significantly lower discontinuation rates due to lack of efficacy for patients taking ETA compared with patients taking IFX or TCZ. ${ }^{52}$ Finally, the Cohort of Arthritis Biologic Users at Kameda Institute registry reported that the drug survival and safety profiles of TCZ are similar to those of TNF inhibitors (IFX, ETA, and ADA). ${ }^{53}$ The results regarding tolerability are summarized in Table 2 . These reports indicate that tolerability of TCZ is comparable to or better than that of TNF inhibitors. 
Table 2 Comparative tolerability of tocilizumab with tumor necrosis factor inhibitors

\begin{tabular}{llllll}
\hline \multirow{2}{*}{$\begin{array}{l}\text { Registry } \\
\text { name }\end{array}$} & $\begin{array}{l}\text { Retention } \\
\text { period }\end{array}$ & \multicolumn{4}{l}{ Drug survival rate (\%) } \\
\cline { 3 - 5 } & TCZ & IFX & ETA & ADA \\
\hline CORRONA $^{45}$ & 24 months & & 63 & 53 & 53 \\
LOHREN $^{46}$ & 2.5 years & & 56 & 72 & 57 \\
SCQM-RA $^{47}$ & 2.5 years & & 51 & 58 & 61 \\
GISEA $^{48}$ & 2.5 years & & 52 & 65 & 52 \\
DANBIO $^{49,50}$ & 96 weeks & 54 & & & \\
& 48 months & & 41 & 56 & 52 \\
BiRD $^{51}$ & 2.5 years & 79 & 47 & 78 & 55 \\
\hline
\end{tabular}

Abbreviations: ADA, adalimumab; BiRD, Biologics for Rheumatic Diseases; CORRONA, Consortium of Rheumatology Researchers of North America; DANBIO, Danish Nationwide Rheumatological Database; ETA, etanercept; GISEA, Gruppo Italiano di Studio sulle Early Arthritides; IFX, infliximab; LOHREN, Lombardy Rheumatology Network; SCQM-RA, Swiss Clinical Quality Management for Rheumatoid Arthritis; TCZ, tocilizumab; TNF, tumor necrosis factor.

\section{Comparative patient focused perspectives, such as quality of life, patient satisfaction/acceptability, adherence, and uptake}

In all Phase III trials modified HAQ-DI scores significantly improved with TCZ treatment. Moreover, based on functional assessment of chronic illness therapy (FACIT), the OPTION and TOWARD studies reported that TCZ had an ameliorative effect, and the Short-Form (SF)36 Health Survey indicated both mental and physical (SF36-mental and SF-physical) effects. ${ }^{11,12}$ In addition, the RADIATE study found that at week 24 versus placebo, TCZ treatment at $8 \mathrm{mg} / \mathrm{kg}$ was associated with significantly greater improvements in HAQ-DI, FACIT, and SF36-physical, and that TCZ treatment at $4 \mathrm{mg} / \mathrm{kg}$ was associated with greater improvements in HAQ-DI and SF36physical. ${ }^{54}$ Components of the Arthritis Impact Measurement Scale 2 (AIMS-2) (eg, physical score, symptom, and affect score) and those of SF36 (eg, bodily pain, general health, vitality, and mental health) improved in 39 patients in a clinical practice after 4 weeks of TCZ therapy, but there was no improvement in the social interaction component of AIMS-2 after 24 weeks of treatment. ${ }^{55}$

The Tocilizumab and DMARDs: Achievements in Rheumatoid Arthritis study reported improvements in diary documented fatigue, pain, and morning stiffness with TCZ treatment. ${ }^{56}$ The mean FACIT-Fatigue score increased from $28.8 \pm 11.2$ at baseline to $35.3 \pm 11.5$ at week 4 and to $37.4 \pm 12.2$ at week 24, and the mean HAQ-DI score decreased from $1.48 \pm 0.65$ to $1.15 \pm 0.68$ at week 4 and to $1.00 \pm 0.75$ at week 24 or the last visit. Favorable mean changes from baseline to week 24 or the last visit were also observed in each of the domains of the SF36, especially in the physical domains. The Treatment Satisfaction Questionnaire for Medication, which was completed at the end of the study, showed a high level of patient agreement/satisfaction for each of the derived domains: "effectiveness" (69.4\%), "side effects" (88.7\%), "convenience" (72.4\%), and "global satisfaction" (74.7\%).

Fatigue represents an important symptom for patients with RA. Chauffier et al assessed the effect of biotherapies on fatigue based on data from ten RCTs involving patients with established RA. ${ }^{57}$ Unfortunately, with respect to fatigue, they found that the overall effect size of all bDMARDs versus placebo at week 24 of treatment is small in established RA. In inadequate responders to sDMARDs, the effect size is similar for TNF inhibitors and nonanti-TNF bDMARDs including TCZ. Strand et al reported that ADA plus MTX significantly improved physical function and health-related quality of life in patients with early RA after 2 years of treatment. ${ }^{58}$ However, no clinically meaningful differences between patients on ADA monotherapy or MTX were observed. In a recent meta-analysis, Callhoff et al studied the impact of bDMARDs including five TNF inhibitors but not TCZ on the physical function of patients with RA, as evaluated by Health Assessment Questionnaire. ${ }^{59}$ Overall, bDMARDs produced greater improvement in physical function than sDMARDs, with an Health Assessment Questionnaire standardized mean difference of 0.44 ( $95 \%$ confidence interval [CI]: 0.38, 0.50). No significant differences between TNF inhibitors were observed.

Huynh et al examined patient treatment preference. ${ }^{60}$ The most frequent reason given for choosing intravenous treatment was "safety" (62\%), followed by "easy to manage" (39\%). The two most frequent reasons given for choosing self-injection at home were "time constraints" and "easy to manage" (both 57\%). The majority of RA patients already treated with bDMARDs in that study preferred the route of administration they were used to. The majority of the patients not currently treated with a bDMARD preferred subcutaneous treatment at home. A feeling of safety was important to patients who preferred intravenous treatment. Health professionals as a group may be biased toward the use of subcutaneous treatment. It is now possible to administer TCZ subcutaneously as well as intravenously. ${ }^{61,62}$ Although subcutaneous injection of TCZ is disadvantageous in heavy patients, the fact that patients can now choose the administration route is a positive development.

\section{Comparison of the cost- effectiveness of TCZ and TNF inhibitors}

Although demonstrations of the outstanding efficacy of TNF inhibitors and TCZ have led to a paradigm shift with respect 
to the management of RA, the relatively high cost of these drugs imposes a large burden on both patients and society. ${ }^{63}$ The Swedish Early Interventions In Rheumatoid Arthritis project demonstrated that drug costs increased primarily due to the introduction of biologics. ${ }^{64}$ Sick leave decreases during the first year, but disability pensions increase, resulting in no change in indirect costs. Over the following years, disability pensions increase further and indirect costs also increase. In the 6 years after diagnosis of early RA, drug costs are partially offset by decreasing outpatient visits, but indirect costs remain unchanged and total costs increase. Therefore, the cost of bDMARDs is a significant problem. bDMARDs significantly increase the quality-adjusted life years (QALYs) gained when compared to MTX alone. QALY is a measure of disease burden affecting the quality and quantity of the life lived. In Finland, TCZ plus MTX was found to be more cost-effective than ADA plus MTX or ETA plus MTX in comparison with MTX alone. ${ }^{65}$ A QALY gained with retail priced (wholesale priced) TCZ plus MTX costs Euro (€)18,957 (€17,057) more than MTX alone. Diamantopoulos et al reported the cost utility of TCZ in RA patients with an inadequate response to sDMARDs from a payer's perspective in Italy. ${ }^{66}$ Replacement of TNF inhibitors (ADA, ETA, and IFX) with TCZ reduces total costs over a patient's lifetime (base-case analysis, TCZ: $€ 141,100$ versus TNF inhibitors: €143,500). Patients receiving TCZ realize more QALYs than patients receiving standard of care (9.8881 QALYs versus 9.3502 QALYs). When TCZ is added to standard of care without replacing TNF inhibitors, the incremental cost-effectiveness ratio becomes $€ 17,100$ per QALY.

In the ADACTA study, economic evaluation of the cost per response or remission of TCZ versus ADA was reported for Spain. ${ }^{67}$ The cost per ACR20/50/70 response is lower with TCZ than with ADA (€8,105/11,162/16,211 versus $€ 11,553 / 20,529 / 31,882)$. The cost of attaining DAS28 remission with TCZ and ADA is $€ 13,204$ and $€ 54,352$, respectively. Treatment with TCZ was dominant in all scenarios analyzed. Similar economic evaluation of TCZ versus ADA from the ADACTA trial was conducted in Australia. ${ }^{68} \mathrm{TCZ}$ monotherapy was found to result in lower total treatment costs (in Australian dollars [\$]) per patient over 24 weeks compared with ADA monotherapy ( $\$ 9,739$ versus $\$ 10,722)$.

In the UK, the addition of TCZ in combination with MTX to treat severe active RA in patients with an inadequate response to sDMARDs was found to produce a gain of 1.17 QALYs per patient, at an incremental cost of UK pound (£)23,253. ${ }^{69}$ This equates to an incremental cost-effectiveness ratio (ICER) of $£ 19,870$. The addition of TCZ in combination with MTX to the current Scottish standard of care in adult TNF inhibitor-inadequate responders with moderate to severe active RA produces a gain of 1.234 QALYs per patient, at an incremental cost of $£ 27,465 .^{70}$ This equates to an ICER of $£ 22,254$. Tanaka et al reported the cost-effectiveness of TCZ in Japan. ${ }^{71}$ The lifetime cumulative costs and QALYs were 35.4 million Japanese yen ( $¥)$ and 11.7 , respectively, in the TCZ group and $¥ 23.3$ million and 9.3, respectively, in the MTX group. The ICER for TCZ was $¥ 4.94$ million, with a $66.2 \%$ probability of falling below the allowable threshold based upon probabilistic sensitivity analysis. These findings suggest that TCZ is more cost-effective than TNF inhibitors, including ADA, ETA, and IFX.

\section{Conclusion and place in therapy}

The property of TCZ and TNF inhibitors is summarized in Figure 2. Based upon recent findings, the EULAR recommendations for the management of RA were updated in 2013. ${ }^{72}$ In patients responding insufficiently to MTX and/or other sDMARDs, with or without glucocorticoids, use of bDMARDs should commence with MTX. First line bDMARDs include TNF inhibitors, abatacept, and TCZ, and under certain circumstances, rituximab. If biologic monotherapy must be initiated, only TCZ has supportive evidence. However, TCZ, TNF inhibitors, and other bDMARDs do not produce beneficial effects in all active RA patients. Therefore, to determine the optimal strategy for using particular bDMARDs in individual RA patients, the characteristic features of these drugs should be clarified. ${ }^{73}$

RA animal models have provided some clarification. The most well-known animal model of RA is collagen-induced arthritis, which involves injection of mice with type II collagen to produce an immune response directed at connective tissues. Both IL- 6 and TNF- $\alpha$ have been shown to play a major role in the development and progression of joint destruction in the collagen-induced arthritis model. Immunization with type II collagen in this model primarily increases the frequency of Th17 cells. Treatment of immunized mice with anti-IL-6 receptor $\mathrm{Ab}$ during priming leads to marked suppression of both the induction of Th17 cells and arthritis development, whereas administration of soluble TNF receptor-Fc fusion protein from day 0 to 14 fails to suppress Th17 differentiation and arthritis development. ${ }^{74}$ Anti-type II collagen Ab-induced arthritis (CAIA) is a model in which the priming phase of T-cell dependent $\mathrm{Ab}$ generation is skipped. Although TNF- $\alpha$ and IL-6 are also elevated in this model, arthritis is suppressed in TNF- $\alpha$ - but not in IL-6-deficient mice, indicating that TNF- $\alpha$ plays a more significant role than IL-6 in joint 


\begin{tabular}{|c|c|c|c|}
\hline & Tocilizun & & TNF inhibitors \\
\hline $\begin{array}{l}\text { Efficacy (with MTX) } \\
\text { on disease activity }\end{array}$ & Excellent & $=$ & Excellent \\
\hline $\begin{array}{l}\text { Efficacy (as monotherapy) } \\
\text { on disease activity }\end{array}$ & Excellent & $>$ & Good \\
\hline $\begin{array}{l}\text { Safety profile } \\
\text { Incidence of AEs } \\
\text { Overall infections } \\
\text { Reactivation of TB } \\
\text { Elevation of T-CHO } \\
\text { GI perforation }\end{array}$ & Tolerable & $\begin{array}{l}= \\
< \\
> \\
>\end{array}$ & Tolerable \\
\hline Tolerability & Good & $>$ or $=$ & Good \\
\hline $\begin{array}{l}\text { Effects on acute-phase } \\
\text { proteins (CRP,SAA, } \\
\text { Hepcidin) }\end{array}$ & Excellent & $>$ & Good \\
\hline Cost-effectiveness & & $>$ & \\
\hline
\end{tabular}

Figure 2 Properties of tocilizumab and tumor necrosis factor inhibitors in the management of rheumatoid arthritis.

Abbreviations: AEs, adverse events; CRP, C-reactive protein; GI, gastrointestinal; MTX, methotrexate; SAA, serum amyloid A; TB, tuberculosis; T-CHO, total cholesterol.

inflammation in CAIA. ${ }^{75}$ These findings suggest that IL- 6 is essential for the induction of immunological abnormalities and the development of arthritis and that the pathological role of IL-6 is different from that of TNF- $\alpha$, which is primarily involved in the development of joint inflammation.

Analyses of various markers during biologic treatment are also helpful to clarify the characteristics of bDMARDs. Both TNF inhibitors and TCZ lead to improvements in serological and urinary markers related to bone and cartilage metabolism. Several immunological studies have sought to clarify the mechanisms underlying the effects of TCZ. Of particular importance is to determine whether TCZ can correct the Th17/Treg imbalance, which is thought to be a fundamental immunological abnormality in $\mathrm{RA} .{ }^{76}$ The results of preliminary studies suggest that inhibition of IL-6 function by TCZ corrects the imbalance between Th17 and Treg cells in the peripheral CD4-positive T-cell population. ${ }^{77,78} \mathrm{In}$ contrast, TNF- $\alpha$ suppresses Treg function by dephosphorylating serine 418 in the $\mathrm{C}$-terminal DNA-binding domain of the forkhead box P3, whereas anti-TNF therapy can restore Treg cell function. ${ }^{79}$ Moreover, a study involving eight patients with RA demonstrated that 6 months of treatment with TCZ causes a selective decrease in IL-21 production by memory/ activated T-cells. ${ }^{80} \mathrm{IL}-21$ is known to promote plasma cell differentiation and induce IgG4 production, and TCZ treatment leads to a reduction in the serum levels of IgG4-specific anticitrullinated peptide antibody, indicating the presence of a pathway involving IL-6, IL-21, and IgG4 autoantibodies in RA. In another study, Roll et al examined the in vivo effect of TCZ on the B-cell compartment in 16 RA patients and found that TCZ induces a significant reduction in peripheral preswitch and postswitch memory B-cells. ${ }^{81}$ In addition, TCZ (but not ETA) significantly reduces somatic hypermutation in immunoglobulin gene rearrangements in preswitch memory B-cells ${ }^{82}$ suggesting modulation of memory B-cells as a possible mechanism for TCZ. Further evaluation is required to clarify the effects of bDMARDs in treating the immunological abnormalities associated with RA.

IL-6, which was found to be identical to hepatocytestimulating factor, induces the expression of various acute phase proteins, such as C-reactive protein, hepcidin, SAA, and fibrinogen, indicating that IL-6 plays a role in the development of systemic inflammatory symptoms, signs, and complications. TCZ treatment is expected to 


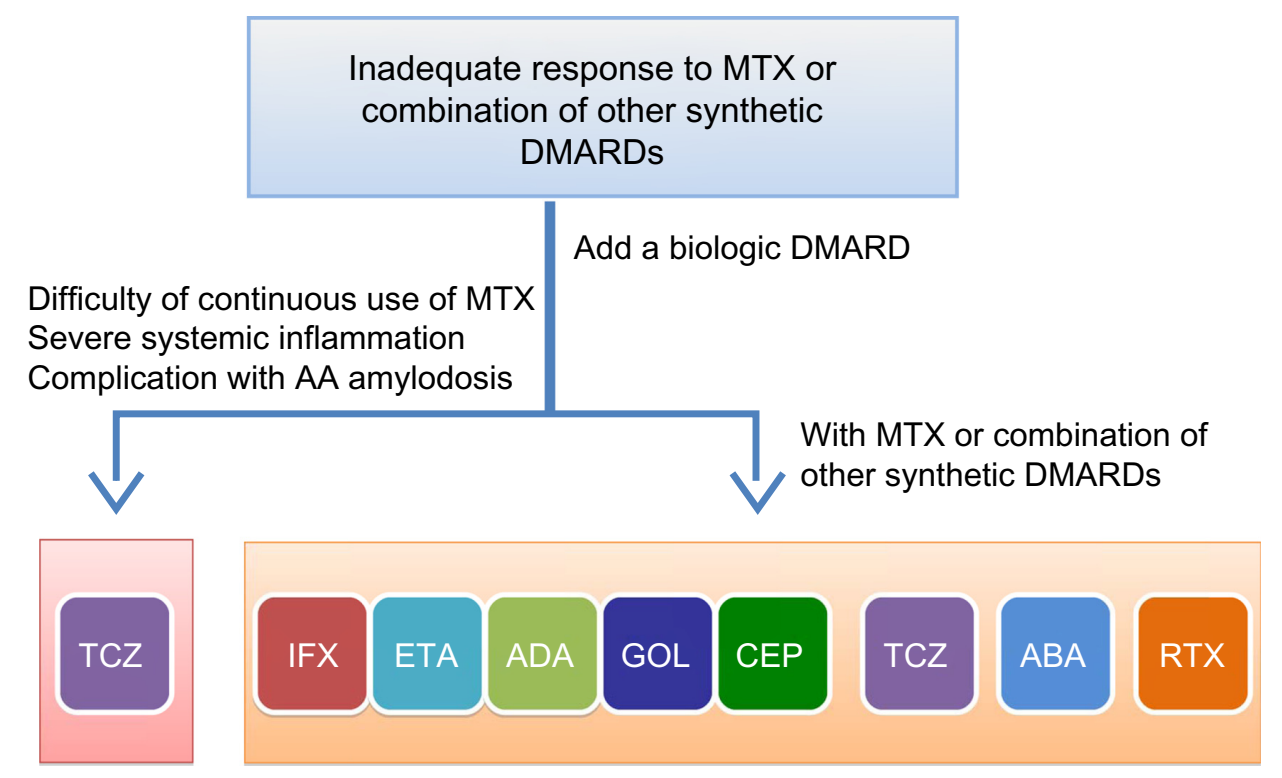

Figure 3 Selection of biologic disease modifying antirheumatic drugs.

Notes: Rheumatoid arthritis patients who fail to respond to methotrexate (MTX) alone or in combination with other synthetic disease modifying antirheumatic drugs (DMARDs) need to be treated with a biologic DMARD. For patients who can continue to receive MTX, any of the seven biologic DMARDs should be selected. These include five tumor necrosis factor inhibitors (infliximab, etanercept, adalimumab, golimumab, and certolizumab pegol), the IL-6 receptor blocker tocilizumab, the T-cell stimulation blocker abatacept, and the B-cell depletory rituximab. Rituximab is recommended to be used for patients who have certain contraindications for other agents such as a recent history of lymphoma, latent tuberculosis with contraindications to the use of chemoprophylaxis, live in a tuberculosis endemic region, or a previous history of demyelinating disease. Tocilizumab may be selected for patients who I) cannot continue treatment with MTX or other synthetic DMARDs, 2) present with severe inflammatory findings, and 3) have or who are at high risk of developing amyloid $A$ amyloidosis.

Abbreviations: ABA, abatacept; ADA, adalimumab; CEP, certolizumab pegol; DMARDs, disease modifying antirheumatic drugs; ETA, etanercept; GOL, golimumab; IFX, infliximab; MTX, methotrexate; RTX, rituximab; TCZ, tocilizumab.

ameliorate the inflammatory effects and inhibit the development of complications. Increased production of hepcidin predominantly induced by IL-6 leads to anemia associated with chronic disorders. ${ }^{83}$ A comparative evaluation of the effects of TCZ and TNF inhibitors on serum hepcidin and anemia found that significant improvement in anemia and reduction in serum hepcidin levels are more pronounced in the TCZ treated patients than in TNF inhibitor treated patients. ${ }^{84}$ Amyloid A amyloidosis is a serious complication of RA, as amyloid fibril deposition causes progressive deterioration in various organs, ${ }^{85}$ although due to a marked progression of antirheumatic treatment, the incidence of amyloid A amyloidosis has recently decreased..$^{86,87}$ SAA is an amyloid fibril precursor protein. Because the synthesis of SAA depends primarily on IL-6, TCZ injection promptly reduces the serum concentration of SAA, just as in the case of C-reactive protein, and the suppressive activity of TCZ on the serum SAA level is more powerful than that of TNF inhibitors. ${ }^{88,89}$ Case reports and series studies published to date have demonstrated the marked ameliorative effect of TCZ on gastrointestinal symptoms and renal dysfunction caused by amyloid A amyloidosis. ${ }^{90-92}$

On the basis of these findings, we suggest that TCZ can be selected as the first line biologic for patients who
1) cannot continue treatment with MTX or other sDMARDs, 2) present with severe inflammatory findings, and 3) have or who are at high risk of developing amyloid A amyloidosis (Figure 3). Moreover, medication adherence and costeffectiveness appears to favor TCZ in comparison with TNF inhibitors. However, further evaluation and clarification of the characteristic features of bDMARDs are essential to determine the optimal treatment for individual RA patients.

\section{Disclosure}

T Tanaka has received a grant and payment for lectures including service on speakers' bureaus from Chugai Pharmaceutical Co, Ltd. Y Hishitani has received a payment for lectures including service on speakers' bureaus from Chugai Pharmaceutical Co, Ltd. A Ogata has received a consulting fee as a medical adviser, a grant, and payment for lectures including service on speakers' bureaus from Chugai Pharmaceutical Co, Ltd.

\section{References}

1. Mclnnes IB, Schett G. The pathogenesis of rheumatoid arthritis. N Engl J Med. 2011;365(23):2205-2219.

2. Smolen JS, Aletaha D, Koeller M, Weisman MH, Emery P. New therapies for treatment of rheumatoid arthritis. Lancet. 2007;370(9602): 1861-1874.

3. Thalayasingam N, Isaacs JD. Anti-TNF therapy. Best Pract Res Clin Rheumatol. 2011;25(4):549-567. 
4. Tanaka T, Ogata A, Narazaki M. Tocilizumab for the treatment of rheumatoid arthritis. Expert Rev Clin Immunol. 2010;6(6):843-854.

5. Tanaka T, Narazaki M, Kishimoto T. Therapeutic targeting of the interleukin-6 receptor. Annu Rev Pharmacol Toxicol. 2012;52: 199-219.

6. Tanaka T, Ogata A, Kishimoto T. Targeting of interleukin-6 for the treatment of rheumatoid arthritis: a review and update. Rheumatol Curr Res. 2013;S4:002.

7. Sato K, Tsuchiya M, Saldanha J, et al. Reshaping a human antibody to inhibit the interleukin-6 dependent tumor cell growth. Cancer Res. 1993;53(4):851-856

8. Jones G, Sebba A, Gu J, et al. Comparison of tocilizumab monotherapy versus methotrexate monotherapy in patients with moderate to severe rheumatoid arthritis: the AMBITION study. Ann Rheum Dis. 2010;69(1):88-96.

9. Nishimoto N, Hashimoto J, Miyasaka N, et al. Study of active controlled monotherapy used for rheumatoid arthritis, an IL-6 inhibitor (SAMURAI): evidence of clinical and radiographic benefit from an x-ray reader-blinded randomized controlled trial of tocilizumab. Ann Rheum Dis. 2007;66(9):1162-1167.

10. Nishimoto N, Miyasaka N, Yamamoto K, et al. Study of active controlled tocilizumab monotherapy for rheumatoid arthritis patients with an inadequate response to methotrexate (SATORI): significant reduction in disease activity and serum vascular endothelial growth factor by IL-6 receptor inhibition therapy. Mod Rheumatol. 2009;19(1):12-19.

11. Smolen JS, Beaulieu A, Rubbert-Roth A, et al; OPTION Investigators. Effect of interleukin-6 receptor inhibition with tocilizumab in patients with rheumatoid arthritis (OPTION study): a double-blind, placebocontrolled, randomized trial. Lancet. 2008;371(9617):987-997.

12. Genovese MC, McKay JD, Nasonov EL, et al. Interleukin-6 receptor inhibition with tocilizumab reduces disease activity in rheumatoid arthritis with inadequate response to disease-modifying antirheumatic drugs: the tocilizumab in combination with traditional diseasemodifying antirheumatic drug therapy study. Arthritis Rheum. 2008;58(10):2968-2980

13. Emery P, Keystone E, Tony HP, et al. IL-6 receptor inhibition with tocilizumab improves treatment outcomes in patients with rheumatoid arthritis refractory to anti-tumor necrosis factor biologicals: results from a 24-week multicentre randomized placebo controlled trial Ann Rheum Dis. 2008;67(11):1516-1523.

14. Kremer JM, Blanco R, Brzosko M, et al. Tocilizumab inhibits structural joint damage in rheumatoid arthritis patients with inadequate responses to methotrexate: results from the double-blind treatment phase of a randomized placebo-controlled trial of tocilizumab safety and prevention of structural joint damage at one year. Arthritis Rheum. 2011;63(3): 609-621.

15. Weinblatt ME, Keystone EC, Furst DE, et al. Adalimumab, a fully human anti-tumor necrosis factor alpha monoclonal antibody, for the treatment of rheumatoid arthritis in patients taking concomitant methotrexate: the ARMADA trial. Arthritis Rheum. 2003;48(1):35-45.

16. Breedveld FC, Weisman MH, Kavanaugh AF, et al. The PREMIER study: A multicenter, randomized, double-blind clinical trial of combination therapy with adalimumab plus methotrexate versus methotrexate alone or adalimumab alone in patients with early, aggressive rheumatoid arthritis who had not had previous methotrexate treatment. Arthritis Rheum. 2006;54(1):26-37.

17. Maini R, St Clari EW, Breedveld F, et al. Infliximab (chimeric antitumour necrosis factor alpha monoclonal antibody) versus placebo in rheumatoid arthritis patients receiving concomitant methotrexate: a randomised phase III trial. ATTRACT Study Group. Lancet. 1999;354(9194):1932-1939.

18. Breedveld FC, Emery P, Keystone E, et al. Infliximab in active early rheumatoid arthritis. Ann Rheum Dis. 2004;63(2):149-155.

19. Keystone EC, Genovese MC, Klareskog L, et al. Golimumab, a human antibody to tumour necrosis factor alpha given by monthly subcutaneous injections, in active rheumatoid arthritis despite methotrexate therapy: the GO-FORWARD Study. Ann Rheum Dis. 2009;68(6):789-796.
20. Keystone E, van der Heijde D, Mason D Jr, et al. Certolizumab pegol plus methotrexate is significantly more effective than placebo plus methotrexate in active rheumatoid arthritis: findings of a fifty-two-week, phase III, multicenter, randomized, double-blind, placebo-controlled, parallel-group study. Arthritis Rheum. 2008;58(11):3319-3329.

21. Moreland LW, Schiff MH, Baumgartner SW, et al. Etanercept therapy in rheumatoid arthritis. A randomized, controlled trial. Ann Intern Med. 1999; 130(6):478-486.

22. Klareskog L, van der Heijde D, de Jager JP, et al; TEMPO (Trial of Etanercept and Methotrexate with Radiographic Patient Outcomes) study investigators. Therapeutic effect of the combination of etanercept and methotrexate compared with each treatment alone in patients with rheumatoid arthritis: double-blind randomised controlled trial. Lancet. 2004;363(9410):675-681.

23. Gabay C, Emery P, van Vollenhoven R, et al; ADACTA Study Investigators. Tocilizumab monotherapy versus adalimumab monotherapy for treatment of rheumatoid arthritis (ADACTA): a randomised, double-blind, controlled phase 4 trial. Lancet. 2013;381(9877):1541-1550.

24. Bergman GJ, Hochberg MC, Boers M, Wintfeld N, Kielhorn A, Jansen JP. Indirect comparison of tocilizumab and other biologic agents in patients with rheumatoid arthritis and inadequate response to diseasemodifying antirheumatic drugs. Semin Arthritis Rheum. 2010;39(6): 425-441.

25. Gallego-Galisteo M, Villa-Rubio A, Alegre-del Rey E, MarquezFernandez E, Ramos-Baez JJ. Indirect comparison of biological treatments in refractory rheumatoid arthritis. J Clin Pharm Ther. 2012;37(3): 301-307.

26. Turkstra E, Ng SK, Scuffham PA. A mixed treatment comparison of the short-term efficacy of biologic disease modifying anti-rheumatic drugs in established rheumatoid arthritis. Curr Med Res Opin. 2011;27(10): 1885-1897.

27. Salliot C, Finckh A, Katchamart W, et al. Indirect comparisons of the efficacy of biological antirheumatic agents in rheumatoid arthritis in patients with an inadequate response to conventional disease-modifying antirheumatic drugs or to an anti-tumour necrosis factor agent: a metaanalysis. Ann Rheum Dis. 2011;70(2):266-271.

28. Orme ME, Macgilchrist KS, Mitchell S, Spurden D, Bird A. Systematic review and network meta-analysis of combination and monotherapy treatments in disease-modifying antirheumatic drug-experienced patients with rheumatoid arthritis: analysis of American College of Rheumatology criteria scores 20,50, and 70. Biologics. 2012;6: $429-464$.

29. Pierreisnard A, Issa N, Barnetche T, Richez C, Schaeverbeke T. Meta-analysis of clinical and radiological efficacy of biologics in rheumatoid arthritis patients naive or inadequately responsive to methotrexate. Joint Bone Spine. 2013;80(4):386-392.

30. Jones G, Darian-Smith E, Kwok M, Winzenberg T. Effect of biologic therapy on radiological progression in rheumatoid arthritis: what does it add to methotrexate? Biologics. 2012;6:155-161.

31. Emery P, Sebba A, Huizinga TW. Biologic and oral disease-modifying antirheumatic drug monotherapy in rheumatoid arthritis. Ann Rheum Dis. 2013;72(12):1897-1904.

32. Dougados M, Kissel K, Sheeran T, et al. Adding tocilizumab or switching to tocilizumab monotherapy in methotrexate inadequate responders: 24-week symptomatic and structural results of a 2-year randomised controlled strategy trial in rheumatoid arthritis (ACT-RAY). Ann Rheum Dis. 2013;72(1):43-50.

33. Takahashi N, Kojima T, Kaneko A, et al. Clinical efficacy of abatacept compared to adalimumab and tocilizumab in rheumatoid arthritis patients with high disease activity. Clin Rheumatol. 2014;33(1):39-47.

34. Schiff MH, Kremer JM, Jahreis A, Vernon E, Isaacs JD, van Vollenhoven RF. Integrated safety in tocilizumab clinical trials. Arthritis Res Ther. 2011;13(5):R141.

35. Genovese MC, Rubbert-Roth A, Smolen JS, et al. Longterm safety and efficacy of tocilizumab in patients with rheumatoid arthritis: a cumulative analysis of up to 4.6 years of exposure. J Rheumatol. 2013;40(6): $768-780$. 
36. Koike $T$, Harigai $M$, Inokuma $S$, et al. Effectiveness and safety of tocilizumab: postmarketing surveillance of 7901 patients with rheumatoid arthritis in Japan. J Rheumatol. 2014;41(1):15-23.

37. Singh JA, Wells GA, Christensen R, et al. Adverse effects of biologics: a network meta-analysis and Cochrane overview. Cochrane Database Syst Rev. 2011;16(2):CD008794.

38. Jain A, Singh JA. Harms of tumor necrosis factor inhibitions in rheumatic diseases: a focused systematic review of the literature. Immunotherapy. 2013;5(3):265-299.

39. Gómez-Reino JJ, Carmona L, Valverde VR, Mola EM, Montero MD; BIOBADASER Group. Treatment of rheumatoid arthritis with tumor necrosis factor inhibitors may predispose to significant increase in tuberculosis risk: a multicenter active-surveillance report. Arthritis Rheum. 2003;48(8):2122-2127.

40. Tubach F, Salmon D, Ravaud P, et al; Research Axed on Tolerance of Biotherapies Group. Risk of tuberculosis is higher with anti-tumor necrosis factor monoclonal antibody therapy than with soluble tumor necrosis factor receptor therapy: the three-year prospective French Research Axed on Tolerance of Biotherapies registry. Arthritis Rheum. 2009;60(7):1884-1894.

41. van Vollenhoven RF, Nishimoto N, Yamanaka H. Experience with Mycobacterium tuberculosis infection reported in the tocilizumab worldwide RA safety database. Ann Rheum Dis. 2009;68(Suppl 3):567.

42. Ogata A, Mori M, Hashimoto S, et al. Minimal influence of tocilizumab on IFN-gamma synthesis by tuberculosis antigens. Mod Rheumatol. 2010;20(2):130-133.

43. Gout T, Ostör AJ, Nisar MK. Lower gastrointestinal perforation in rheumatoid arthritis patients treated with conventional DMARDs or tocilizumab: a systematic literature review. Clin Rheumatol. 2011;30(11):1471-1474.

44. Mclnnes IB, Thompson L, Giles JT, et al. Effect of interleukin-6 receptor blockade on surrogates of vascular risk in rheumatoid arthritis: MEASURE, a randomised, placebo-controlled study. Ann Rheum Dis. Epub December 24, 2013

45. Greenberg JD, Reed G, Decktor D, et al; CORRONA Investigators. A comparative effectiveness study of adalimumab, etanercept and infliximab in biologically naive and switched rheumatoid arthritis patients: results from the US CORRONA registry. Ann Rheum Dis. 2012;71(7):1134-1142.

46. Marchesoni A, Zaccara E, Gorla R, et al. TNF-alpha antagonist survival rate in a cohort of rheumatoid arthritis patients observed under conditions of standard clinical practice. Ann NY Acad Sci. 2009;1173:837-846.

47. Du Pan SM, Dehler S, Ciurea A, et al; Swiss Clinical Quality Management Physicians. Comparison of drug retention rates and causes of drug discontinuation between anti-tumor necrosis factor agents in rheumatoid arthritis. Arthritis Rheum. 2009;61(5):560-568.

48. Iannone F, Ferraccioli G, Gremese E, Lapadula G; for the Group Italiano di Studio sulle Early Arthritis (GISEA). Drug survival on TNF inhibitors: 2003-2004 data from Italian National Register (GISEA Registry). Ann Rheum Dis. Epub December 24, 2013.

49. Leffers HCB, Østergaard M, Glintborg B, et al. Three-year drug survival and effectiveness of Abatacept and Tocilizumab in patients with rheumatoid arthritis treated in routine care. Results from the Nationwide Danish Danbio Registry. Arthritis Rheum. 2013;65(Suppl 10):S612.

50. Hetland ML, Christensen IJ, Tarp U, et al; All Departments of Rheumatology in Denmark. Direct comparison of treatment responses, remission rates, and drug adherence in patients with rheumatoid arthritis treated with adalimumab, etanercept, or infliximab: results from eight years of surveillance of clinical practice in the nationwide Danish DANBIO registry. Arthritis Rheum. 2010;62(1):22-32.

51. Hishitani Y, Ogata A, Shima Y, et al. Retention of tocilizumab and antitumour necrosis factor drugs in the treatment of rheumatoid arthritis Scand J Rheumatol. 2013;42(4):253-259.

52. Sakai R, Tanaka M, Nanki T, et al; REAL Study Group. Drug retention rates and relevant risk factors for drug discontinuation due to adverse events in rheumatoid arthritis patients receiving anticytokine therapy with different target molecules. Ann Rheum Dis. 2012;71(11):1820-1826.
53. Yoshida $\mathrm{K}$, Tokuda Y, Oshikawa $\mathrm{H}$, et al. An observational study of tocilizumab and TNF- $\alpha$ inhibitor use in a Japanese community hospital: different remission rates, similar drug survival and safety. Rheumatology (Oxford). 2011;50(11):2093-2099.

54. Strand V, Burmester GR, Ogale S, Devenport J, John A, Emery P. Improvements in health-related quality of life after treatment with tocilizumab in patients with rheumatoid arthritis refractory to tumour necrosis factor inhibitors: results from the 24-week randomized controlled RADIATE study. Rheumatology (Oxford). 2012;51(10):1860-1869.

55. Fusama M, Nakahara H, Hamano $Y$, et al. Improvement of health status evaluated by Arthritis Impact Measurement Scale (AIMS-2) and Short Form-36 (SF-36) in patients with rheumatoid arthritis treated with tocilizumab. Mod Rheumatol. 2013;23(2):276-283.

56. Feist E, Rubbert-Roth A, Kaufmann J, et al. Effectiveness after 4 and 24 weeks and safety of the novel interleukin- 6 receptor inhibitors tocilizumab (TCZ) in patients with active rheumatoid arthritis (RA)analysis of the patient-reported outcomes (PRO) in the TAMARA study. Ann Rheum Dis. 2010;69(Suppl 3):544.

57. Chauffier K, Salliot C, Berenbaum F, et al. Effect of biotherapies on fatigue in rheumatoid arthritis: a systematic review of the literature and meta-analysis. Rheumatology (Oxford). 2012;51(1):60-68.

58. Strand V, Rentz AM, Cifaldi MA, Chen N, Roy S, Revicki D. Healthrelated quality of life outcomes of adalimumab for patients with early rheumatoid arthritis: results from a randomized multicenter study. J Rheumatol. 2012;39(1):63-72.

59. Callhoff J, Weiß A, Zink A, Listing J. Impact of biologic therapy on functional status in patients with rheumatoid arthritis - a meta-analysis. Rheumatology (Oxford). 2013;52(12):2127-2135.

60. Huynh T, Østergaard A, Egsmose C, et al. Patients and health professional preferences to route of administration of biologics agents for RA treatment. Ann Rheum Dis. 2013;72(Suppl 3):431.

61. Burmester GR, Rubbert-Roth A, Cantagrel A, et al. A randomised, double-blind, parallel-group study of the safety and efficacy of subcutaneous tocilizumab versus intravenous tocilizumab in combination with traditional disease-modifying antirheumatic drugs in patients with moderate to severe rheumatoid arthritis (SUMMACTA study). Ann Rheum Dis. 2014;73(1):69-74.

62. Ogata A, Tanimura K, Sugimoto T, et al. A phase 3 study of the efficacy and safety of subcutaneous versus intravenous tocilizumab monotherapy in patients with rheumatoid arthritis (MUSASHI). Arthritis Care Res (Hoboken). Epub August 27, 2013.

63. Tsao NW, Bansback NJ, Shojania K, Marra CA. The issue of comparators in economic evaluations of biologic response modifiers in rheumatoid arthritis. Best Pract Res Clin Rheumatol. 2012;26(5):659-676.

64. Hallert E, Husberg M, Kalkan A, Skogh T, Bernfort L. Early rheumatoid arthritis 6 years after diagnosis is still associated with high direct costs and increasing loss of productivity: the Swedish TIRA project. Scand $J$ Rheumatol. Epub December 19, 2013.

65. Soini EJ, Hallinen TA, Puolakka K, Vihervaara V, Kauppi MJ. Costeffectiveness of adalimumab, etanercept, and tocilizumab as first-line treatments for moderate-to-severe rheumatoid arthritis. J Med Econ. 2012;15(2):340-351.

66. Diamantopoulos A, Benucci M, Capri S, et al. Economic evaluation of tocilizumab combination in the treatment of moderate-to-severe rheumatoid arthritis in Italy. J Med Econ. 2012;15(3):576-585.

67. Navarro Sarabia F, Blanco FJ, Alvaro Gracia JM, et al. [Economic evaluation of rheumatoid arthritis monotherapy with tocilizumab and adalimumab]. Rev Esp Salud Publica. 2013;87(4):343-350. Spanish.

68. Ngo P, Sorathia RC, Todd C, Jones G, Nash P. Australian economic evaluation of tocilizumab (TCZ) monotherapy vs adalimumab (ADA) monotherapy in patients with rheumatoid arthritis (RA) based on the ADACTA trial. Internal Medicine Journal. 2013;43(12):12.

69. Papadakis K, McNamara S, Wintfeld N, et al. A UK cost-effectiveness analysis on the use of tocilizumab (Roactemra ${ }^{\circledR}$ ) with methotrexate in the treatment of adults with moderate to severe active rheumatoid arthritis who have failed to respond adequate to one or more DMARDs. Ann Rheum Dis. 2010;69(Suppl 3):389. 
70. McNamara SK, Papadakis KN, Wintfeld N, et al. An economic evaluation on the use of tocilizumab (Roactemra ${ }^{\circledR}$ ) with methotrexate in the treatment of adults with moderate to severe active rheumatoid arthritis who have failed to respond adequately to an anti-TNF drugs in Scotland. Ann Rheum Dis. 2010;69(Suppl 3):389.

71. Tanaka E, Inoue E, Hoshi D, et al. Cost-effectiveness of a humanized anti-intereleukin-6 (IL-6) receptor monoclonal antibody, tocilizumab, in rheumatoid arthritis using IORRA cohort database. Ann Rheum Dis. 2012;71(Suppl 3):668.

72. Smolen JS, Landewe R, Breedveld FC, et al. EULAR recommendations for the management of rheumatoid arthritis with synthetic and biological disease-modifying antirheumatic drugs: 2013 update. Ann Rheum Dis. Epub October 25, 2013.

73. Ogata A, Hirano T, Hishitani Y, Tanaka T. Safety and efficacy of tocilizumab for the treatment of rheumatoid arthritis. Clin Med Insights Arthritis Musculoskelet Disord. 2012;5:27-42.

74. Fujimoto M, Serada S, Mihara M, et al. Interleukin-6 blockade suppresses autoimmune arthritis in mice by the inhibition of inflammatory Th17 responses. Arthritis Rheum. 2008;58(12):3710-3719.

75. Kagari T, Doi H, Shimozato T. The importance of IL-1 beta and TNFalpha, and the noninvolvement of IL-6, in the development of monoclonal antibody-induced arthritis. J Immunol. 2002;169(3):1459-1466.

76. Tanaka T. Can IL-6 blockade rectify imbalance between Tregs and Th17 cells? Immunotherapy. 2013;5(7):695-697.

77. Samson M, Audia S, Janikashvili N, et al. Brief report: inhibition of interleukin-6 function corrects Th17/Treg cell imbalance in rheumatoid arthritis patients. Arthritis Rheum. 2012;64(8):2499-2503.

78. Pesce B, Soto L, Sabugo F, et al. Effect of interleukin-6 receptor blockade on the balance between regulatory $\mathrm{T}$ cells and $\mathrm{T}$ helper type 17 cells in rheumatoid arthritis patients. Clin Exp Immunol. 2013;171(3): 237-242.

79. Nie H, Zheng Y, Li R, et al. Phosphorylation of FOXP3 controls regulatory $\mathrm{T}$ cell function and is inhibited by TNF-a in rheumatoid arthritis. Nat Med. 2013;19(3):322-328.

80. Carbone G, Wilson A, Diehl SA, Bunn J, Cooper SM, Rincon M Interleukin-6 receptor blockade selectively reduces IL-21 production by CD4 T cells and IgG4 autoantibodies in rheumatoid arthritis. Int $J$ Biol Sci. 2013;9(3):279-288.

81. Roll P, Muhammad K, Schumann M, et al. In vivo effects of the antiinterleukin-6 receptor inhibitor tocilizumab on the B cell compartment Arthritis Rheum. 2011;63(5):1255-1264.
82. Muhammad K, Roll P, Seibold T, et al. Impact of IL-6 receptor inhibition on human memory B cells in vivo: impaired somatic hypermutation in preswitch memory B cells and mutational targeting in memory B cells. Ann Rheum Dis. 2011;70(8):1507-1510.

83. Nemeth E, Rivera S, Gabayan V, et al. IL-6 mediates hypoferremia of inflammation by inducing the synthesis of the iron regulatory hormone hepcidin. J Clin Invest. 2004;113(9):1271-1276.

84. Song SN, Iwahashi M, Tomosugi N, et al. Comparative evaluation of the effects of treatment with tocilizumab and TNF- $\alpha$ inhibitors on serum hepcidin, anemia response and disease activity in rheumatoid arthritis patients. Arthritis Res Ther. 2013;15(5):R141.

85. Obici L, Merlini G. AA amyloidosis: basic knowledge, unmet needs and future treatments. Swiss Med Wkly. 2012;142:w13580.

86. Laiho K, Tiitinen S, Kaarela K, Helin H, Isomaki H. Secondary amyloidosis has decreased in patients with inflammatory joint disease in Finland. Clin Rheumatol. 1999;18(2):122-123.

87. Immonen K, Finne P, Gronhagen-Riska C, et al. A marked decline in the incidence of renal replacement therapy for amyloidosis associated with inflammatory rheumatic diseases - data from nationwide registries in Finland. Amyloid. 2011;18(1):25-28.

88. Tanaka T, Hagihara K, Hishitani Y, Ogata A. Tocilizumab for the treatment of AA amyloidosis. In: Guvenc IA, editor. Amyloidosis - An Insight to Disease of Systems and Novel Therapies. Croatia: INTECH Open Access Publisher; 2011:155-170.

89. Okuda Y, Ohnishi M, Matoba K, et al. Comparison of the clinical utility of tocilizumab and anti-TNF therapy in AA amyloidosis complicating rheumatic diseases. Mod Rheumatol. 2014;24(1):137-143.

90. Nishida S, Hagihara K, Shima Y, et al. Rapid improvement of AA amyloidosis with humanised anti-interleukin 6 receptor antibody treatment. Ann Rheum Dis. 2009;68(7):1235-1236.

91. Hakala M, Immonen K, Korpela M, Vasala M, Kauppi MJ. Good medium-term efficacy of tocilizumab in DMARD and anti-TNF- $\alpha$ therapy resistant reactive amyloidosis. Ann Rheum Dis. 2013;72(3): 464-465.

92. Miyagawa I, Nakayamada S, Saito K, et al. Study on the safety and efficacy of tocilizumab, an anti-IL-6 receptor antibody, in patients with rheumatoid arthritis complicated with AA amyloidosis. Mod Rheumatol. Epub October 21, 2013.
Biologics: Targets \& Therapy

\section{Publish your work in this journal}

Biologics: Targets \& Therapy is an international, peer-reviewed journal focusing on the patho-physiological rationale for and clinical application of Biologic agents in the management of autoimmune diseases, cancers or other pathologies where a molecular target can be identified. This journal is indexed on PubMed Central, CAS, EMBase, Scopus

\section{Dovepress}

and the Elsevier Bibliographic databases. The manuscript management system is completely online and includes a very quick and fair peerreview system, which is all easy to use. Visit http://www.dovepress. com/testimonials.php to read real quotes from published authors. 